\title{
Research on the Relationship between Organizational Embeddedness and Job Performance among the Generation after 90s $\rightarrow$ Self Efficacy as Mediating Variable
}

\author{
Song Ying* \\ Room 705 Students Apartment \\ Wuhan University of Science and Technology \\ Wuhan
}

\author{
LI Yongzhou \\ Wuhan University of Science and Technology \\ Wuhan
}

\begin{abstract}
This study is aimed at the generation after 90s who have high mobility and individual independence. It investigates the relationship between the organizational embeddedness and job performance among this group. This study introduces selfefficacy as mediating variable. The results show that organizational embeddedness has a significant positive effect on self-efficacy. This study proposes a human resource management practices and measures by establishing a clear post-demand quality model, paying attention to employee's personality, constructing smooth communication channels among company and forming a targeted incentive model.
\end{abstract}

Keywords-Employees of 90s, Organizational embeddedness, Self-efficacy, Job performance

\section{INTRODUCTION}

Under the background of economic globalization and the mobile Internet era, the flow of capital and information tends to globalization. In addition, the flow velocity tends to be just-intime. Employees of 90s are the first generation under this background and they have the characteristics of "net generation" and "globalization". Their channels and tools to knowledge and information are more diverse while the timeliness is stronger. Compared with other countries, the 90s generation of our country has the characteristics of "one generation". As the only one child in the family, the employees of 90s gain more care and attention from their parents, so they are used to become the focus of attention. This group has the following characteristics: more personal tendency, more distinctive personality characteristics, strong self-awareness, strong independence and the growth environment lacks of brothers and sisters. These characteristics make this generation more selfish and self-oriented. At present, there are more and more 90s employees in the job market and this number continues increasing. They are full of vitality and passion that bring new energy to the development of enterprises. These characteristics put forward new challenges to the management of enterprises. As far as the cultural atmosphere of our country is concerned, the social reality that pay much attention to interpersonal network and human relationship makes "job embeddedness" become a suitable model for China's current national conditions. Based on this, this paper studies the impact of corporate culture, work atmosphere and self-efficacy on their job performance from the personality and behavioral characteristics of 90 s employees as the starting point. This paper intends to construct the relationship between organizational embeddedness, self-efficacy and job performance to provide management advice for the recruitment and employment of enterprises.

\section{RESEARCH HYPOTHESIS AND MODEL CONSTRUCTION}

\section{A. Organizational embeddedness and job performance}

Mitchell and Lee put forward the theory of "Job Embeddedness" based on the interpersonal network relations of human in social life. They construct three dimensions of coupling, matching and sacrifice in job embeddedness. Organizational embeddedness is the attachment and dependence of the individual to the organization and their recognition towards the organization's culture and atmosphere. In addition, it is the employee's sense of belonging to the organization and the psychological perception of employees who are willing to pay in the organization. Jiang (2012) analysis found that the negative correlation between organizational embeddedness and turnover intention was more significant in female dominated organizations and public institutions. The influence of community embeddedness on turnover intention is stronger in collectivism culture[1]. The study of Holtom (2013) found that the predictive power of job embeddedness on turnover enhanced with the increase of working years[2]. Organizational embeddedness has an impact on the performance of 90s' employees from three aspects. They have higher demands for spiritual pursuits. If the benefits offered by the company can stimulate their job satisfactions, their turnover may be reduced. It can promote their subjective initiative into the work.

\section{B. Self efficacy and job performance}

Fan, Litchfield and Islam (2013) put forward the concept of self-efficacy in work and society. They defined it as “employee's confidence to develop with other employee and 
maintain effective interpersonal relationships with them in its participation in work-related social activities as well as its organization”[3]. Compared with ability level and the strength of an individual's actual capacity, self-efficacy can accurately predict a person's professional behavior[4]. A study of 2000 managers in 41 different organizations from 12 countries found that several competencies were related to self-efficacy, so it is an important variable to predict the performance of managers[5]. From Chen Bo’s (2012) analysis, we can find that there was a significant correlation between the dimensions of self-efficacy (cognitive and developmental self-efficacy, perceived self-efficacy innovation and learning efficacy, sense of self-efficacy) and the dimensions of job performance (task performance, contextual performance).

\section{The mediating effect of self-efficacy on job embeddedness and job performance}

The higher matching between staff and organization, the stronger coupling it is and the greater sacrifice from leaving the organization. In this condition, employees will show a better sense of self-efficacy in organizational decision making and organizational role cognition, so they will take the initiative to play more self-ability to solve the difficulties encountered in the work. The final performance of the work will be more adapted to the needs of the organization, so they will show higher job performance. In the study of LEE (2004), job embeddedness has a significant positive effect on job performance. This paper studies the relationship between the three variables that are organizational embeddedness, selfefficacy and job performance. It mainly focuses on the relationship between organizational embeddedness and job performance. In the analysis and discussion, the self-efficacy is the mediator variable. The basic relationship between the three variables and the hypothetical model is shown in Fig. 1.

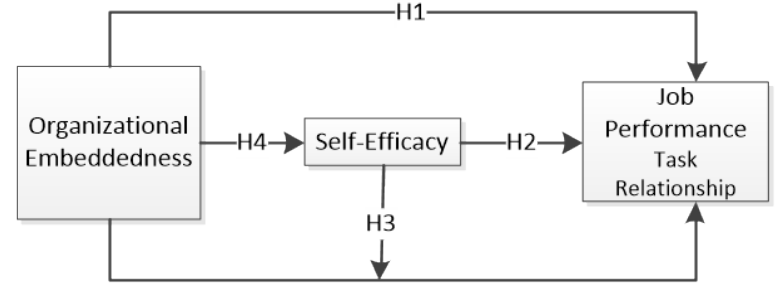

Fig. 1. Basic relationship between job embeddedness, self-efficacy and job performance

\section{DATA ANALYSIS AND MODEL CHECKING}

In the official survey, a total of 345 questionnaires were collected from different industries in Wuhan, Shanghai, Shandong and Shenzhen. Among which there are 248 samples from 90s generation. When removes obvious data missing, similar answers questionnaires and less than a minute sample, there are ultimately 225 valid questionnaires. The effective rate was $90.72 \%$.

\section{A. Analysis of confirmatory factor}

Confirmatory factor tests are performed in AMOS 22 and it mainly investigates weather the reliability of each variable (C.R), the average variance extraction quantity (AVE) and the fitness index of the surface meet the requirements or not. It would modify factors according to the correction coefficient to make the scale have good convergent validity. The results are shown in TABLE I.

TABLE I. RESULTS OF CONFIRMATORY FACTOR ANALYSIS

\begin{tabular}{rccccccccc}
\hline & C.R. & AVE & $\chi^{2} / \mathrm{df}$ & NFI & IFI & TLI & CFI & RMSEA & RMR \\
\hline Connection & 0.76 & 1.67 & & & & & & & \\
Fit & 0.85 & 0.55 & 3.13 & 0.942 & 0.953 & 0.903 & 0.957 & 0.079 & 0.049 \\
Sacrifice & 0.74 & 0.52 & & & & & & & \\
Self Efficacy & 0.94 & 2.36 & 1.72 & 0.942 & 0.922 & 0.954 & 0.942 & 0.080 & 0.042 \\
Performance & 0.86 & 1.92 & 1.93 & 0.971 & 0.984 & 0.971 & 0.983 & 0.068 & 0.017 \\
\hline
\end{tabular}

embeddedness has a positive impact on the job performance of

\section{B. Hypothesis test}

In this paper, AMOS22 software is used to analyze the latent variable path of structural equation modeling. Then, it builds the model 1 based on the assumption H3 to examine the mediating effect of self-efficacy on organizational embeddedness and job performance. The fitness index is obtained according to the adaptation statistics of the preset model (see TABLE II.). As can be seen from Fig.2, the standard path of organizational coupling to job performance of employees is $0.47(\mathrm{P}<0.001)$, the standard path coefficient of organizational matching to job performance is $0.42(\mathrm{p}<0.001)$ and the path coefficient of organizational sacrifice to job performance is $0.18 \quad(\mathrm{P}=0.15)$. This shows that job employees, so $\mathrm{H} 1$ can pass the examination.

TABLE II. FITNESS INDEX OF STRUCTURAL EQUATION MODEL

\begin{tabular}{cccccccc}
\hline Model & $\chi^{2} / \mathrm{df}$ & GFI & CFI & NFI & IFI & TLI & RMR \\
\hline Model1 & 3.67 & 0.94 & 0.93 & 0.90 & 0.93 & 0.91 & 0.06 \\
Model2 & 2.89 & 0.89 & 0.88 & 0.82 & 0.88 & 0.85 & 0.09 \\
\hline
\end{tabular}




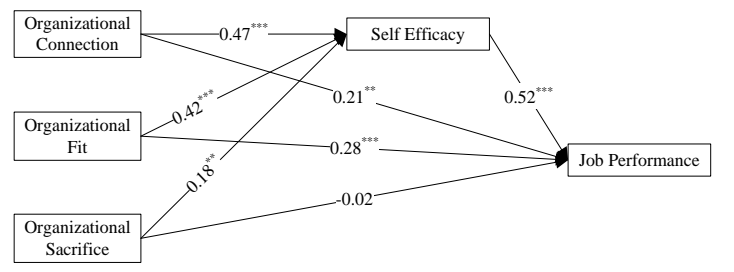

Fig. 2. The Mediating Effect of self-efficacy on organizational embeddedness and job performance of 90s employees (model 1)

Self Efficacy $\quad 0.63^{* * *} \longrightarrow$ Job Performance

Fig. 3. The effect of self-efficacy on job performance

As Fig. 3, the standardized path of self-efficacy to job performance is $0.63 \quad(\mathrm{P}<0.001)$. Self-efficacy plays an intermediary role between organizational embeddedness and job performance among 90s’ employees.

\section{DATA ANALYSIS RESULTS}

The results show that organizational embeddedness is an effective predictor of job performance. The effect of organizational matching and organizational coupling are positively correlated at 0.01 level on job performance. The stronger the employee attachment to the organization, the more likely it is to show a higher performance. The impact of organizational sacrifice on job performance not passed that means the cost of employees leaving the organization will not directly affect performance.

The staff with higher organizational embeddedness has a closer relationship with organization. They are easier to conduct their organizational work, so this part of the staff will show a better sense of self-efficacy in the face of problems. 90s' employees have a strong sense of self-awareness and they think they have great ability to solve problems. The stronger the connection with the organization, the more likely it is to form a sense of self-efficacy in the organization.

There is a significant positive correlation between selfefficacy and job performance in 90s' employees. The sense of self efficacy of employees is a perception that they are able to solve the problem. When this kind of cognition is stronger, the staff may show strong enthusiasm and initiative in solving the problem, so the job performance will be higher.

Through the regression analysis, this paper finds that the self-efficacy plays a intermediary role in the relationship between organizational coupling, organizational matching and job performance. That is, when organizational embeddedness has an impact on job performance through self-efficacy, it also directly affects job performance. The sense of self-efficacy is a completely mediator in the relationship between organizational sacrifice and job performance. That is to say, the cost of leaving the company will affect the performance of the work directly.

\section{CONCLUSION AND PROSPECT}

Enterprises should pay more consideration to the matching degree and connection condition between employees and enterprises in the recruitment of staff. In the recruitment and selection, the enterprise should introduce the talent evaluation system to regard the individual's personality characteristics as a basis for consideration. They should find more suitable people rather than blindly select high-quality and highly educated personnel so as to reduce unnecessary waste of talent and staff turnover costs.

Enterprises should maintain the good relationship between competition and cooperation among employees. They should attach importance on the training and stimulation of employee's innovation consciousness. The enterprise can introduce the content of the psychological counseling in the daily training to conduct psychological counseling for employees. In order to avoid the unnecessary loss of talent, they should actively deal with the turnover phenomenon of the department.

Enterprises should provide a reasonable promotion mechanism and long-term security mechanism for employees. In order to achieve this, they can introduce long-term incentives and enhance seniority wages. In addition, they can improve the cost of leaving the organization to some extent to increase the employee's organizational embeddedness.

Enterprises should strengthen humane care and respect for personality. They can establish a relationship between employees and organizations based on emotion. In addition, they should respect employee's personality. For different staff, they can develop different evaluation system. With the peopleoriented idea, they should reject the dogmatic corporate charter. Finally, enterprise should pay attention to personal development and emotional support to create a loving organization.

\section{REFERENCES}

[1] Jiang K, Liu D, McKay P F, et al. When and How is Job Embeddedness Predictive of Turnover? A Meta -analytic Investigation [J]. Journal of Applied Psychology, 2012(5):1077 -1096.

[2] Holtom B C, Tidd S T, Mitchell T R, et al. A Demonstration of the Importance of Temporal Considerations in the Prediction of Newcomer Turnover[J]. Human Relations,2013(10):1337-1352.

[3] Fan J, Litchfield R C, Islam S, et al. Workplace Social Self-Efficacy[J]. Journal of Career Assessment, 2013, 21:91-110.

[4] Betz, N. E \& Hackett, G. The Relationship of Career-related SelfEfficacy Expectations to perceived Career Options in College Women and Men [J]. Journal of Counseling Psychology, 1981, (28):399-410.

[5] Boyatzis R E. The Competent Manager: A Model for Effective Perfrmamce[M].N Y:John Wiley \& Sons,1982. 